\title{
Biological characterisation of superficial bladder cancer by bivariate cytokeratin 7/DNA analysis, flow cytometric assessment of MIB-1, and an immunohistochemical study
}

Elena Leonardi ${ }^{\mathrm{a}, *}$, Paolo Dalla Palma ${ }^{\mathrm{a}}$, Alessandro Reich ${ }^{\mathrm{b}}$, Orazio Caffo ${ }^{\mathrm{c}}$ and Lucio Luciani ${ }^{\mathrm{b}}$

${ }^{a}$ Department of Pathology, St. Chiara Hospital, Trento, Italy

${ }^{\mathrm{b}}$ Department of Urology, St. Chiara Hospital, Trento, Italy

${ }^{\mathrm{c}}$ Department of Oncology, St. Chiara Hospital, Trento, Italy

Received August 1999

Accepted 4 October 2000

A total of 238 cases of bladder carcinoma stages Ta, Tis, T1 were submitted prospectively to multiparameter flow cytometry and immunohistochemical study in order to determine the biological aggressiveness of the tumour. DNA index (DI), S-phase fraction (SPF) obtained by bivariate cytokeratin 7/DNA analyses, and the immunohistochemical evaluation of p53 and MIB-1 were studied in relation to the traditional prognostic factors in bladder cancer (stage and grade). The variance analysis results showed that DNA aneuploidy was significantly associated with high stage $(p=$ $0.0001)$, high grade $(p=0.0001)$, high SPF value $\geqslant 5.5 \%$ $(p=0.0001)$ MIB-1 positivity $\geqslant 31 \%(p=0.0001)$ and high expression of $\mathrm{p} 53$ (staining involving $>50 \%$ of cells, $p=0.0001$ ). Even if there was no statistical significance the hypotetraploid class $(1.70<\mathrm{DI}<1.89)$ showed poor prognostic biomarkers more frequently than the other aneuploid classes. Out of 238 cases, 101 were also submitted to flow cytometric measurement of MIB-1 (fMIB-1) to study the corre-

\footnotetext{
*Corresponding author: Elena Leonardi, Department of Pathology, Ospedale S. Chiara, via Crosina Sartori 6, Trento, 38100, Italy. Tel.: +39 461 903303; Fax: +39 461 903389; E-mail: leonardi@ tn.aziendasanitaria.trentino.it.
}

lation between cell proliferation and DNA content. Data obtained from fresh, 3:1 methanol/acetone fixed samples were compared with values obtained from both cell cycle analysis methods and routine application of the MIB-1 immunostaining in histological sections. fMIB-1 values were positively correlated with SPF values $(r=0.801, p<0.01)$ and $\mathrm{S}+\mathrm{G} 2 \mathrm{M}$ fraction (percentage of cells in S and in G2M phases) $(r=0.763, p<0.01)$ but no correlation with paraffin sections was found. A fMIB-1 value $>7 \%$ was strongly associated with aneuploidy $(p=0.0001)$. The determination of DNA content coupled with the study of the epithelial (cytokeratin 7) and proliferative (MIB-1) markers could be useful in providing important information on the biological behaviour of superficial bladder tumours.

Keywords: DNA content, bladder cancer, p53, cell proliferation, MIB-1

\section{Introduction}

Superficial transitional cell carcinoma of the bladder represents a disease entity characterised by a wide variation in its natural course and prognosis. Alongside relatively benign non invasive tumours some neoplasms show a highly aggressive attitude because of their high biological potential to progress and metastatize. Often an unpredictable evolution occurs although the parameters in general use today such as T-classification and histological grade, support a low malignant potential [11,37].

In order to improve the prognostic value of the traditional indicators and a better monitoring of patients after therapy, flow cytometric procedures have been introduced as an objective and measurable adjunct to clinical morphology. Flow cytometric analyses give 
additional information with regard to cellular heterogeneity, state of tumour proliferation and predictive response to therapy. In particular DNA status $[2,16$, $19,33,39-42]$ and proliferative activity estimation [3, $6,14,22,36]$ are reliable prognostic indicators in bladder cancer. A bivariate approach based on the staining of the epithelial component of the tumour with low molecular weight cytokeratin is more accurate in determining DNA content particularly in cases where the inflammatory component is most relevant $[18,43]$. Immunohistochemical determination of mutational inactivation of the p53 tumour-suppressor gene can also provide useful information about bladder cancer behaviour. Previous studies on p53 protein demonstrated its fundamental role in determining the aggressive clinical outcome of the superficial disease $[12,20,21,26,28$, 30,31]. Quantification of the "tumour growth fraction", the percentage of cycling cells, represents another of the major objectives in tumour prognosis and diagnosis $[1,4,15,25,29,38,45]$. Among the several methods in use today [7] tumour cell proliferation is currently estimated either from S-phase values obtained by applying mathematical models to DNA histograms or by quantifying, on tumour sections, the proliferation associated molecules such as Ki67, MIB-1, PCNA with immunohistochemical procedures. In this study we performed a flow cytometric MIB-1 analysis on fresh tumour samples to assess the expression of this antigen usually considered as a valuable marker in superficial bladder cancer $[3,22,23]$. In order to verify the feasibility and usefulness of this approach, flow cytometric MIB-1 data were compared with data obtained from both cell cycle analysis methods and routine application of the immunostaining in histological sections.

The aim of our prospective study was to investigate the behaviour of superficial bladder cancer by characterising biologically tumour tissue with a number of markers which include DNA content, S-phase fraction obtained by flow cytometric analysis of DNA content with cytokeratin 7 , an antigen expressed in urothelial cells, flow cytometric measurement of MIB-1 in fresh tumour tissue and the immunohistochemical expression of p53 and MIB-1 in routine parallel sections of the neoplasms. We also attempted to study the relation among distinct ploidy classes, obtained by subgrouping the DNA Index (DI) values, with the strongest expression of unfavourable markers (high MIB-1 and p53 values).

Data obtained from flow cytometric and immunohistochemical approaches were compared with established prognostic factors (stage and grade) in order to assess their potential usefulness as prognostic markers in superficial bladder cancer.

\section{Materials and methods}

\subsection{Patients}

The study population consisted of 238 patients with histologically proven superficial transitional cell carcinoma of the bladder (stage Ta Tis T1) collected prospectively in the Pathology Department of S. Chiara Hospital (Trento, Italy) during the period 1995-1997 (Table 1). The diagnostic samples were obtained from cold transurethral resections biopsies and examined fresh in order to perform the flow cytometric procedures.

There were 199 men $(84 \%)$ with a mean age of 65.1 years (range $27-89$ years; STD $=11.4$ ) and 39 women (16\%) with a mean age of 66.7 years (range 20-90 years, STD = 13.3). Criteria for inclusion into the study were: patients with a diagnosis of bladder cancer, data available on T-classification and histological grade. Clinical characteristics of the study population are summarised in Table 1.

\subsection{Sample preparation for flow cytometry}

The fresh surgical specimens were immediately mechanically disaggregated with a scalpel in PBS (Cell dissociation solution non enzymatic, cat. $n^{\circ} \mathrm{C}-1544$, Sigma St. Louis, MO, USA). Cell suspensions were filtered through a $50 \mu \mathrm{m}$ nylon mesh, centrifuged at $600 \mathrm{rpm}$ and stored at $-80^{\circ} \mathrm{C}$ in a propylen tube containing $1 \mathrm{ml}$ of cryopreservative solution composed of fetal bovine serum (cat. ${ }^{\circ}$ F-3018, Sigma, St. Louis, MO, USA), $10 \%$ and dimethylsulfoxide (cat. $\mathrm{n}^{\circ} \mathrm{D}-$ 5879, Sigma, St. Louis, MO, USA) 10\% in RPMI 1640 Medium (cat. $\mathrm{n}^{\circ}$ R-8758, Sigma, St. Louis, MO, USA).

Table 1

Clinico-pathologic characteristics of the study population

\begin{tabular}{lr} 
Total number of patients \\
Clinico-pathologic stage \\
Ta \\
Tis & 238 \\
T1 & \\
Grading & $9(88 \%)$ \\
G1 & $20(8 \%)$ \\
G2 & $80(34 \%)$ \\
G3 & $119(50 \%)$ \\
\hline
\end{tabular}

* Out of 20 T1 tumours 6 cases showed a carcinoma in situ in the same or adjacent biopsies.

Stage was assigned according to the TNM classification; grading was assigned according to Bloom and Richardson. 


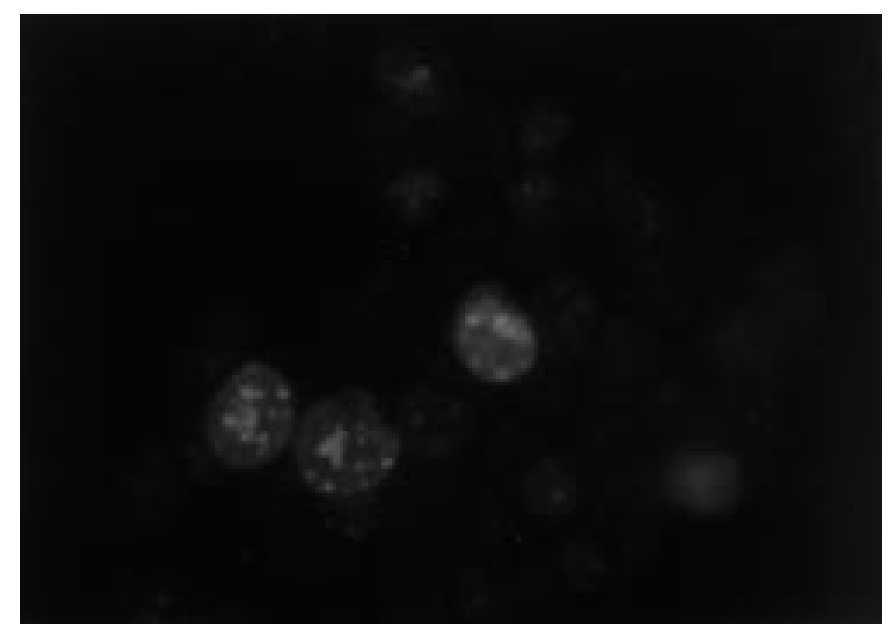

Fig. 1. Dot-like intranuclear staining of MIB-1 in a single-cell suspension prepared from a superficial transitional cell carcinoma of the bladder, grade 2 (original magnification $\times 1000$ ). Cells were fixed with methanol/acetone and stained with an indirect method of immunofluorescence.

At the time of analysis, tubes were rapidly thawed at $37^{\circ} \mathrm{C}$ and centrifuged at $600 \mathrm{rpm}$ for $10 \mathrm{~min}$. An indirect immunofluorescent staining was applied on pellets previously fixed for nuclear antigen (MIB-1) and cytoplasmatic antigen (cytokeratin 7).

\subsubsection{MIB-1 immunostaining}

Pellets were fixed for 20 minutes with $1 \mathrm{ml}$ of a solution composed of absolute methanol and acetone (3 parts of methanol and 1 part of acetone) previously refrigerated at $-20^{\circ} \mathrm{C}$. After a brief centrifugation the pellets were resuspended within the washing solution (normal goat serum and phosphate buffer $1: 10)$ and centrifuged. The pellets were divided in two aliquots and respectively incubated with MIB-1 (MIB-1, Mouse IgG1, cat. ${ }^{\circ}$ M-520, Medac Diagnostika, Valter Occhiena) and mouse isotypic IgG (Mouse IgG1 Kappa, MOPC-21, cat. n M-5284 Sigma, St. Louis, MO) dilutions $1: 10$ for $1 \mathrm{~h}$ at room temperature. After washing the pellets were incubated with goat anti-mouse IgG Fab specific FITC conjugate (anti-mouse IgG cat. $\mathrm{n}^{\circ}$ F-2653 Sigma, St. Louis, MO) dilution $1: 100$, for 30 minutes at room temperature in the dark.

At the end of this step the washed pellets were stained with 5 gamma propidium iodide with RNase and Nonidet $-\mathrm{P} 40$ overnight at $4^{\circ} \mathrm{C}$.

Before flow cytometric analysis aliquots of stained cell suspensions were smeared and examined with fluorescent microscope to verify the MIB-1 labelled nuclei. The presence of a dot-like (Fig. 1) or an homogeneous diffuse intranuclear staining was accounted to positive expression of MIB-1.

\subsubsection{Cytokeratin 7 immunostaining}

Pellets were fixed with cold $70 \%$ ethanol for 30 minutes at $4{ }^{\circ} \mathrm{C}$. After centrifugation pellets were washed twice in a washing solution composed of $5 \%$ fetal bovine serum, $0.1 \%$ albumin bovine (cat. $n^{\circ}$ A-2153, Sigma, St. Louis, MO) in PBS.

The first aliquot was incubated $1 \mathrm{~h}$ at $4^{\circ} \mathrm{C}$ with a monoclonal antibody against cytokeratin 7 (KER 7, cat. $\mathrm{n}^{\circ} \mathrm{M}-7018$ DAKO) diluted $1: 20$ in PBS. The pellet for negative control was incubated for 1 hour at $4{ }^{\circ} \mathrm{C}$ with a non specific isotypic mouse IgG1 (Mouse IgG1 Kappa, MOPC-21, cat. n ${ }^{\circ}$ M-5284 Sigma, St. Louis, $\mathrm{MO})$ in the same experimental conditions as the test sample. At the end of the incubation time, cell suspensions were washed in $1 \mathrm{ml}$ of washing solution that had been added to each tube and mixed.

Tubes were immediately centrifuged at $600 \mathrm{rpm}$ for 10 minutes. Cell pellets were incubated with rabbit anti-mouse IgG FITC (cat. $\mathrm{n}^{\circ}$ F0313, DAKO, Glostrup, Denmark) diluted 1:20 for 30 minutes and finally stained with 5 gamma of propidium iodide (PI) solution overnight.

In order to evaluate the presence of cytokeratinpositive cells an aliquot of cell suspension was smeared and examined by fluorescent microscope.

\subsection{Flow cytometric analysis}

FCM analysis was performed on a FACS can flow cytometer (Becton Dickinson Immunocytometry Systems, Mountain View, CA), equipped with a $15 \mathrm{~mW}$ argon laser $(488 \mathrm{~nm})$ and doublet discrimination module. Cell FIT Software Package was used for instru- 

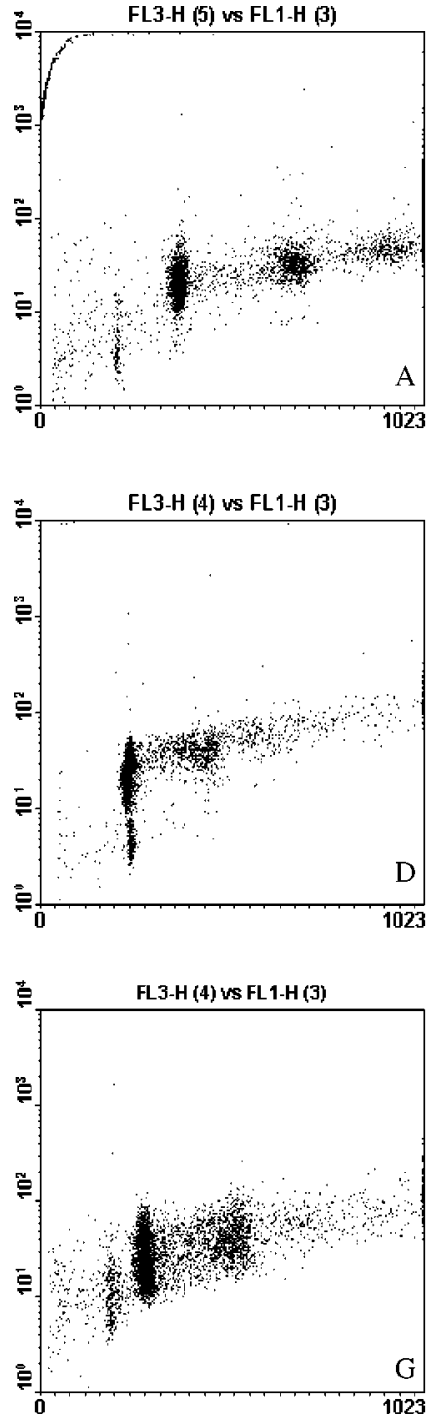
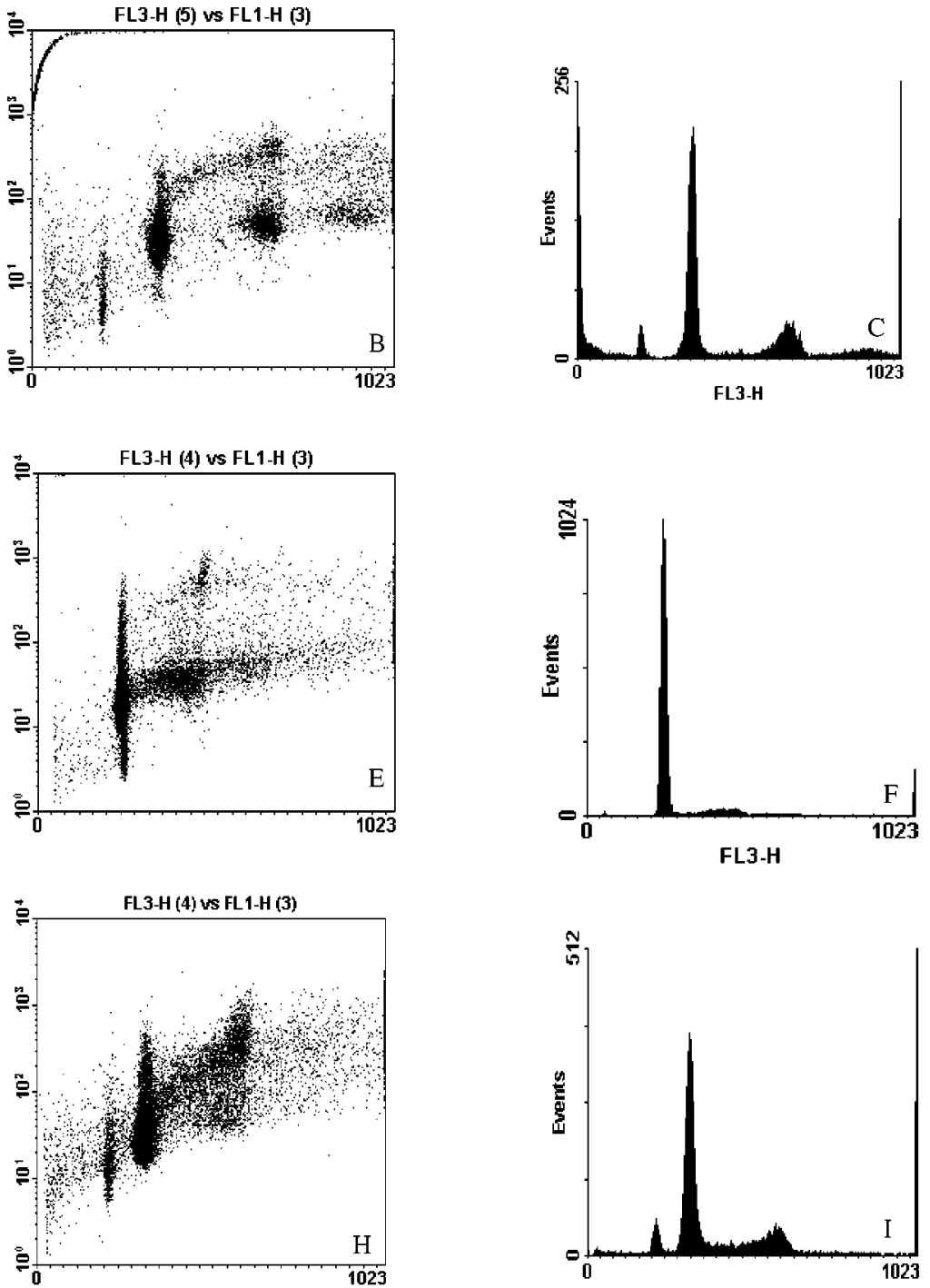

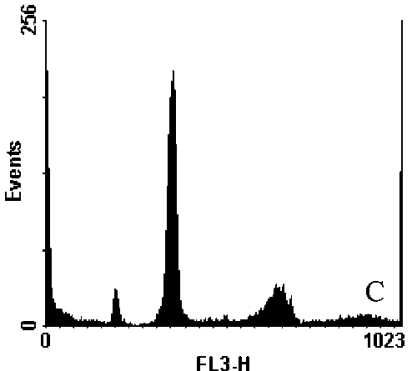

FL3-H

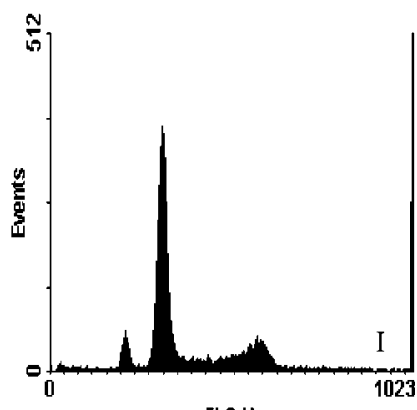

Fig. 2. Examples of bivariate MIB-1/DNA FCM analyses. Dot-plots relate to MIB-1 expression (FL1-H) versus DNA content (FL3-H). Figures A, B, C refer to isotypic controls; D, E, F to test sample with positivity for MIB-1 of 11, 8 and 28\%, respectively; G, H, I to DNA histograms with DIs $=1.77 ; 1 ; 1.51$, respectively.

ment set-up, data acquisition and histogram deconvolution. Instrument set-up and calibration were performed using a propidium iodide stained diploid normal tissue. For MIB-1/DNA samples almost 15,000 events were recorded. For cytokeratin 7/DNA samples at least 20,000 events were recorded in list mode data using 1024 channels.

\subsubsection{Gating methods}

To assess the MIB-1 antigen expression a threshold level of fluorescence for the negative control was empirically fixed allowing not more than $1 \%$ of positive cells in the control sample. All the events falling above this cutoff are considered positive for the expression of MIB-1 (Fig. 2).

In order to calculate the percentage of the positive events WinMdi software was used (Win MDI Version 2.1.4).

A population with positive staining for cytokeratin 7 was identified by comparing FL3-H and FL1-H dot plots of the tested sample to the negative control. Samples were considered adequately labelled only if a distinct visually separation in green fluorescence intensity (FL1-H histogram) was present. 


\subsubsection{Histogram interpretation}

Cell cycle analysis was calculated by rectangular curve fitting (RFIT, Becton Dickinson, CellFIT Software) for diploid tumour and by polynomial model (POLY Model) when the sample contained two cell populations with different DNA contents. Histograms including a single G0/G1 peak were considered DNA diploid (DI = 1.00). When more than one G0/G1 peak was present, histograms were classified as follows: DNA hypodiploid (DI $<1.00$ ), DNA near-diploid $(1.00<$ DI $<1.39)$, DNA near-triploid $(1.40<$ DI $<$ $1.69)$, DNA hypotetraploid $(1.70<\mathrm{DI}<1.89)$, DNA tetraploid $(1.90<\mathrm{DI} \leqslant 2.10)$, DNA hypertetraploid (DI $>2.10$ ), DNA multiploid when more than one aneuploid population was found.

Tumours were classified as tetraploid only when a corresponding $\mathrm{G} 2 / \mathrm{M}$ peak in the $8 \mathrm{C}$ region was identifiable. Histograms were considered reliable when CV (coefficient of variation) of the G0/G1 diploid peak was lower than $3.5 \%$. SPF values obtained by biparametric procedure were divided in tertiles: low $(\mathrm{S} \leqslant 1.90 \%)$, medium $(1.91 \%<\mathrm{S}<5.5 \%)$, high $(\mathrm{S} \geqslant 5.5 \%)$.

In order to identify the ploidy class in which a higher frequency of cases with high cellular proliferation (MIB- $1 \geqslant 31 \%$, SPF $\geqslant 5.5 \%$ ) and high expression of p53 (score 2) occured, a subdivision of the cases in six ploidy classes was performed as follows: DNA diploid and peridiploid $(0.90<$ DI $<1.39)$, DNA near-triploid $(1.4<$ DI $<1.69)$, DNA hypotetraploid $(1.70<$ DI $<1.89)$, DNA tetraploid $(1.90<$ DI $<2.10)$, DNA hypertetraploid (DI $>2.10$ ), multiclonal (two or more clones).

\subsection{Statistical analysis}

The differences between diploid and aneuploid cases in terms of stage, grading, MIB-1 value, p53 expression and SPF values were assessed using the one way analysis of variance (ANOVA test). Similarly, after stratifying the DNA index into six classes, the differences in terms of MIB-1 value, p53 expression and SPF values were analysed by ANOVA test; a post hoc multiple comparison test was based on both Duncan's multiple range test and the Sidak's test. These tests allowed us to compare each pairs of means stratified by ploidy classes. The statistical analysis was performed by SPSS software package version 8.0 for Windows.

\section{Immunohistochemistry}

Formalin fixed, paraffin embedded tissues were cut in sections $5 \mu \mathrm{m}$ thick. Antigen retrieval was performed using an $800 \mathrm{~W}$ microwave oven at full power in citrate buffer $\mathrm{pH} 6.0$ for two cycles $10 \mathrm{~min}$ utes each [35]. Slides were incubated overnight at $4^{\circ} \mathrm{C}$ with the following antibodies: MIB-1 (MIB-1, Mouse IgG1, cat. ${ }^{\circ}$ M-520, Medac Diagnostika, Valter Occhiena), p53 (clone DO7, DBA, Milano, Italy) dilution $1: 1000$. Biotinylated anti-mouse $\operatorname{IgG}$ and streptavidin-biotin enhanced immunoperoxidase technique (StrepABComplex/HRP, Duet, Mouse/Rabbit, DAKO, Glostrup, Denmark) were applied in sequence. The immunostaining for MIB-1 was evaluated on the basis of the percentage of stained nuclei counting at least 500 cells in more than 10 high power $(1000 \times)$ representative fields. In cases where intratumoral heterogeneity of staining was seen, examined fields included those with the highest and the lowest percentage of stained cells (Fig. 3). Percentile expression of MIB-1 in neoplastic cells was divided in tertiles: low $(\leqslant 10 \%)$, medium $(11-30 \%)$, high $(\geqslant 31 \%)$.

Quantification of nuclear p53 immunostaining was estimated analysing 10 consecutive $1000 \times$ microscopic fields $(100 \times$ objective and $10 \times$ oculars $)$ containing malignant cells.

A bladder cancer biopsy specimen known to contain a mutational inactivation of p53, as detected by DNA sequence analysis, and showing an intense positivity for p53 was used as positive control. As negative control each tumour was incubated with nonimmune mouse immunoglobulin instead of the primary antibody. All slides were reviewed independently in a blinded fashion by two of us (E.L. and P.D.P). The immunohistochemical positivity for p53 was scored by using an arbitrary system as follows: score 0, p53 negative carcinomas;

score 1: focal darkly staining areas or moderate staining of $<50 \%$ of cells; score 2 : dark nuclear staining that involves $>50 \%$ of cells (Fig. 4).

P53 was evaluated in this way following the suggestion of a previous report [26] in which positive immunohistochemical staining for p53 represented a good indication of mutation in the p53 gene if the designation of positive immunostaining was limited to the cases where more than one-half tumour cells were stained instead of occuring as isolated single cells or in small clusters. 


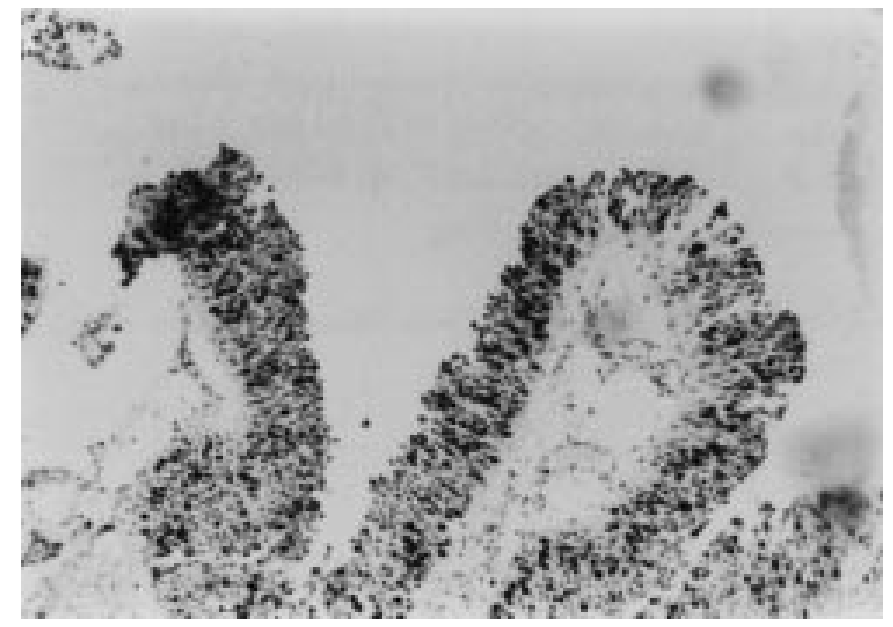

Fig. 3. Immunoreactivity for MIB-1 in transitional cell carcinoma of the bladder, Ta grade 2 (original magnification $\times 250$ ).

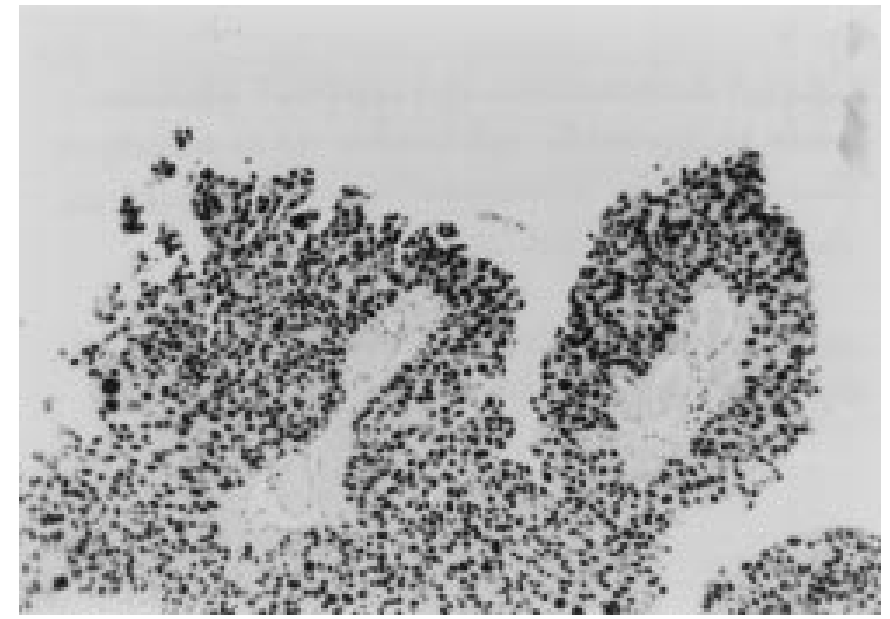

Fig. 4. Expression of p53 in a transitional cell carcinoma of the bladder, Tis, grade 3 (original magnification $\times 250$ ). Immunoreactivity is present in most of the neoplastic cells.

\section{DI distribution of the study population}

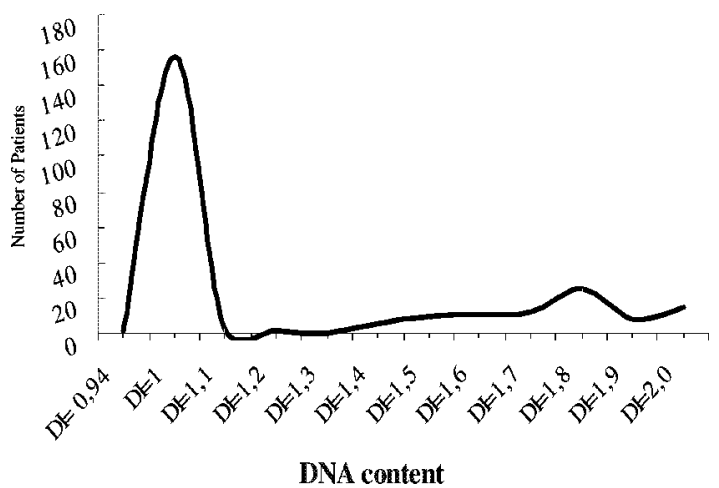

Fig. 5. Distribution of DIs of the study population.

\section{Results}

Out of 238 cases of superficial transitional cell carcinoma of the bladder diploidy was present in 156 cases (66\%) and aneuploidy in 82 cases (34\%).

Distribution of DIs is shown in Fig. 5. Application of bivariate cytokeratin 7/DNA analysis was useful to determine more accurately DNA abnormalities and SPF values without the presence of a contaminanting population such as inflammatory cells and debris which increase the risk of underestimating the S-phase value. In particular the bivariate approach was most useful in cases where a possible misinterpretation of DNA histograms may occur as in hypodiploid or multiclonal cases (Fig. 6). 

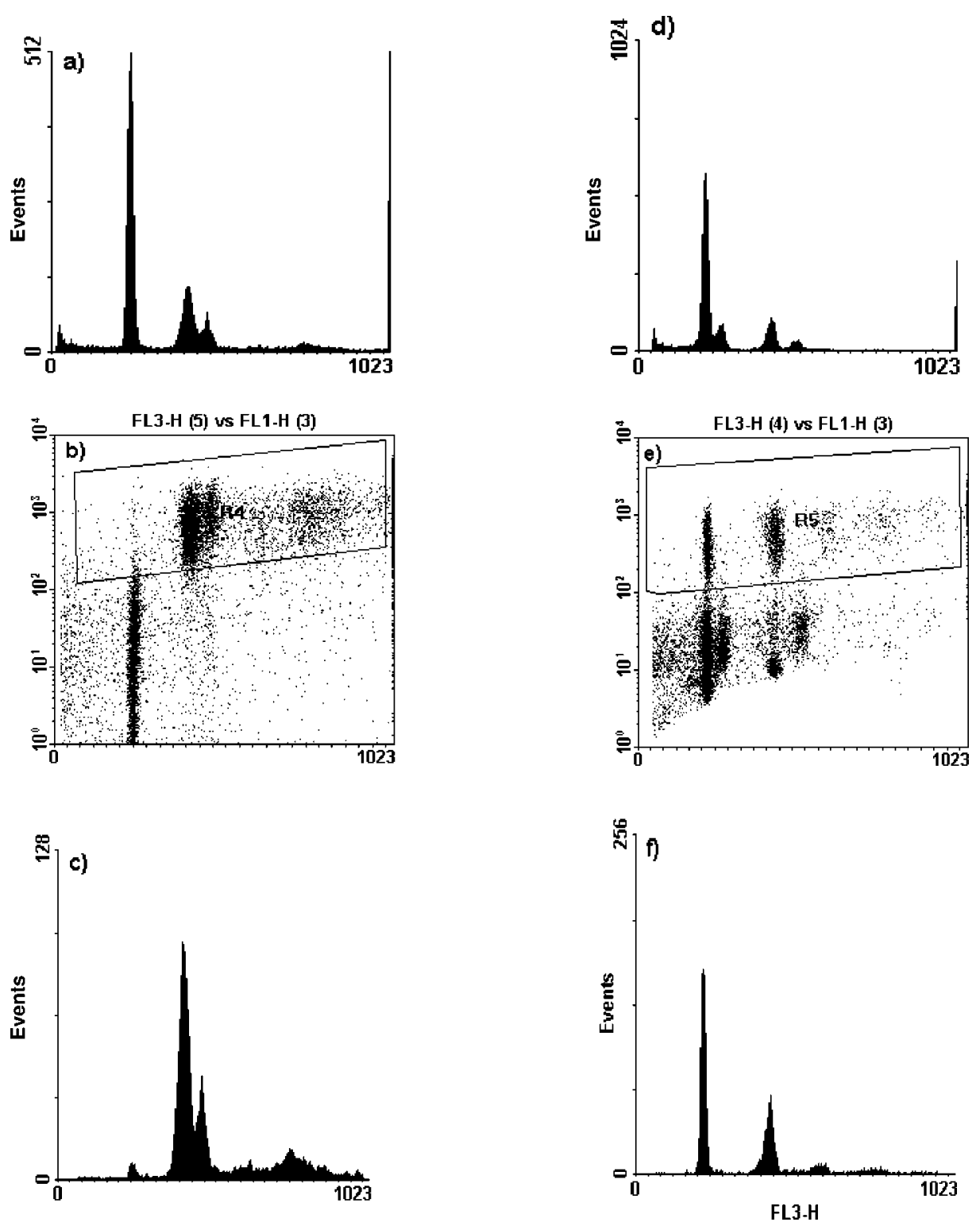

Fig. 6. Examples of bivariate CK7/DNA FCM analyses in superficial transitional cell carcinoma. Ungated DNA histograms (a, d), dot-plots (b, e) and DNA histograms after gating with cytokeratin 7 (c, f); (a) $\mathrm{DI}=1.67+1.90$; (d) $\mathrm{DI}=0.88$ CK-labelled cells were gated to generate histogram (c) and (f) from the epithelial component only.

The SPF percentages were achieved in 222 cases. It was not possible to determine the SPF value in 16 cases due to inadequate fitting of the mathematical models because no distinct $\mathrm{G} 2+\mathrm{M}$ peak for the reference population was visible. A strong correlation between DNA aneuploidy and staging,grading, SPF value $\geqslant 5.5 \%$, MIB- $1 \geqslant 31 \%$ and high expression of p53 (score 2) was found (Table 2).

The post hoc analysis performed by Duncan's test and Sidak's test failed to demonstrate any statistically significant difference among the ploidy classes: the distribution of cases according to MIB-1 values, SPF values and p53 expression is shown in Fig. 7.

Flow cytometric measurement of MIB-1 (fMIB-1) on fresh tissue was evaluated in 101 cases. Not enough quantity of cellular suspension was available for immunostaining in the remaining cases. Preliminary experiments were performed to determine the method of choice to preserve MIB-1 antigen such as paraformaldehyde, ethanol, etc. but without improve- 
Table 2

Correlation of DNA ploidy by biparametric DNA/cytokeratin 7 flow cytometry versus clinico-morphologic and biologic parameters

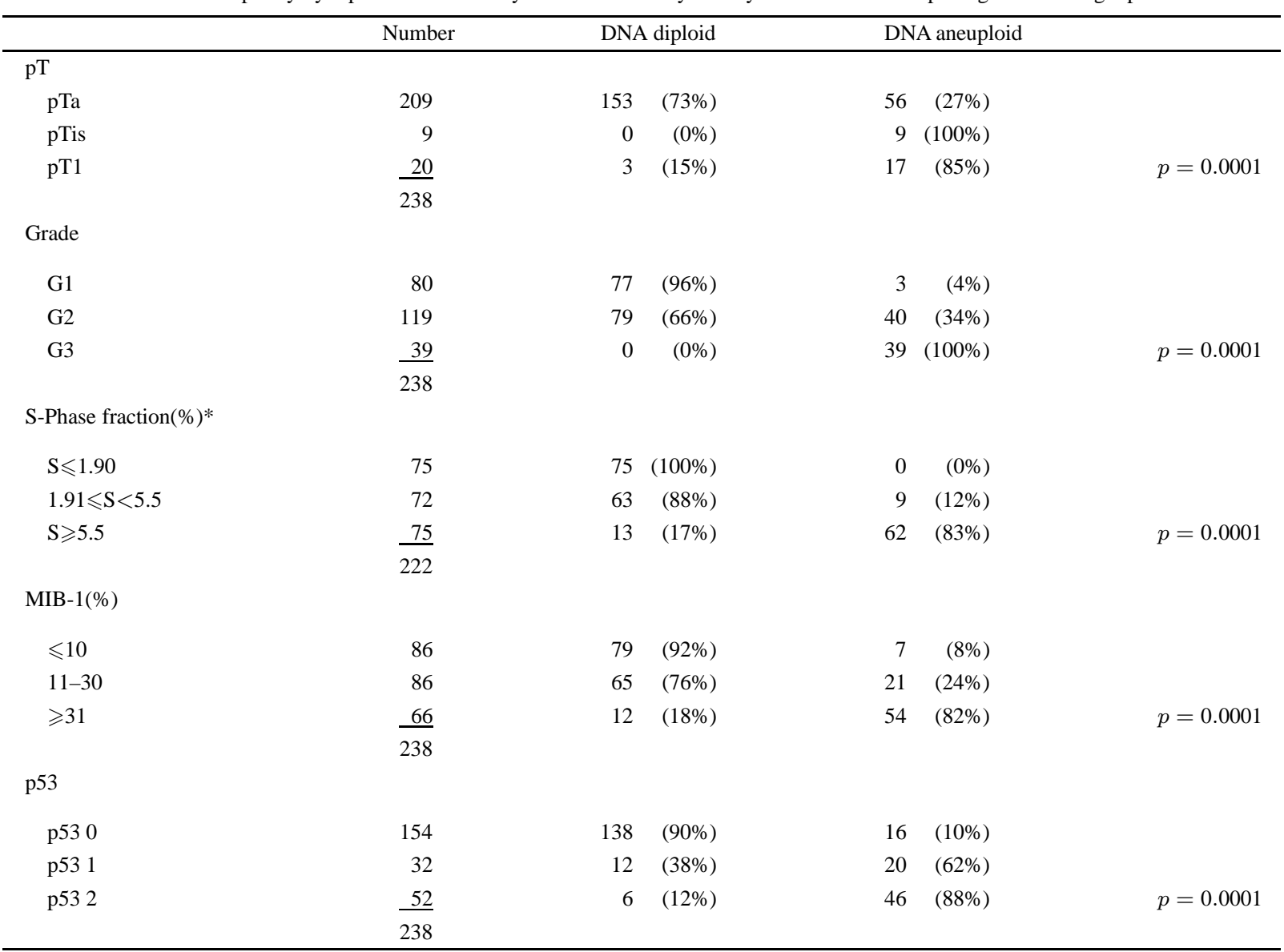

* It was not possible to determine S-phase values in 16 cases due to inadequate fitting of mathematical models.

pT: assigned according to the TNM classification; grade: histological differentiation according to Bloom and Richardson; MIB-1: percentile immunohistochemical expression of MIB-1 in neoplastic cells; SPF: fraction of cells in S phase evaluated by flow cytometry; p53: 0,1,2 immunohistochemical reactivity for p53 (score 0: no positive cells; score 1: positivity involves $<50 \%$ of cells; score 2: positivity cells involves $>50 \%$ ).

ments. In all cases a good distinction between negative and positive cells was obtained (Fig. 2).

The tertiles of fMIB-1 were divided as follows: low fMIB1: $\leqslant 3 \%$, medium fMIB-1: 4-7\%, high fMIB-1: $>7 \%$ The relation between ploidy and tertiles of fMIB1 is represented in Fig. 8.

Most diploid cases exhibited a low fMIB-1 value, while aneuploid cases showed high fMIB-1 values $(>7 \%, p=0.0001)$.

The distribution of fMIB-1 values was as follows: in the lowest tertile diploid (24 cases) and tetraploid (4 cases); in the medium tertile diploid (15 cases) and hypotetraploid (9 cases), in the higher tertile diploid (4 cases), near-triploid (12 cases), hypotetraploid (16 cases), tetraploid (5 cases), hypertetraploid (2 cases) multiclonal ( 8 cases), hypodiploid ( 2 cases). MIB-1 la- beling indices were matched with $\mathrm{SPF}$ and $\mathrm{S}+\mathrm{G} 2 \mathrm{M}$ values by correlation method. The flow MIB-1 values were positively correlated with $\mathrm{S}$-phase values $(r=0.801, p<0.01)$ and $\mathrm{S}+\mathrm{G} 2 \mathrm{M}(r=0.763$, $p<0.01$ ) (Fig. 9). The Pearson's correlation coefficient was significant at 0.01 level. No correlation between flow MIB-1 values and MIB-1 data from paraffin sections were obtained.

\section{Discussion}

Tumour progression in human solid tumours is currently believed to result from genetic instability and consequent acquisition of new genetic properties in some of the tumour cells. However, not all DNA 


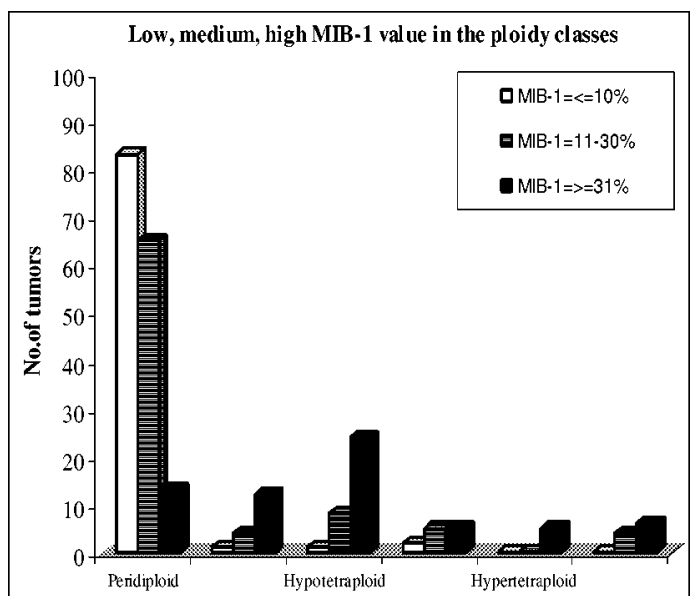

(a)

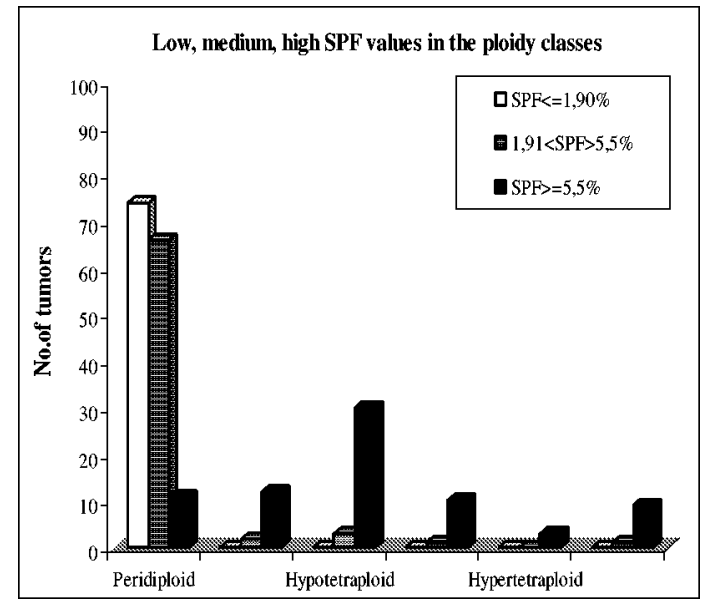

(b)

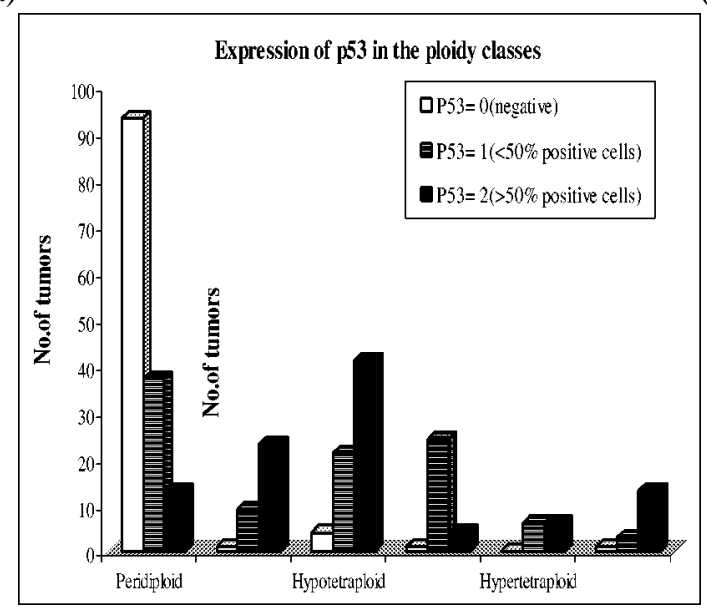

(c)

Fig. 7. Bar histograms showing the relation existing between ploidy classes and MIB-1 (a), SPF values (b) and expression of p53 (c). The hypotetraploid class was the one showing the highest percentage of cases with poor prognostic biomarkers.

changes are biologically functional for tumour progression [5]. Accumulation of specific genetic abnormalities in the same tumour cells such as DNA aneuploidy, loss of function of many suppressor genes or oncogenes activation [34] give the tumour a high malignant potential. An increased cellular proliferation may also be seen as a decisive step for tumour progression [27]. Previous studies in bladder cancer showed that aneuploidy and in particular DNA hypertetraploidy and DNA multiploidy represent markers of poor outcome [33]. Moreover, p53 abnormalities $[12,20,21,26,28,30,31]$ and an increase in cellular proliferation [22,23] were reported to play a key role in the transition from pre-invasive to invasive disease. Among the available methods which estimate cellular proliferation those based on the determination of the proliferation-associated markers are the more fre- quently employed. The antigen known as MIB-1 has been proposed as the indicator of choice for tumour cell proliferation studies. Some reports showed that in bladder cancer immunohistochemical expressions of $15 \%$ [23] and 25\% [44] of MIB-1 were considered as cut-off values to distinguish between tumours with favourable course and tumours with an aggressive disease in terms of recurrence or progression to invasive cancer. Moreover by using immunohistochemical procedures it is possible to evaluate not only the quantification of this antigen but also its expression pattern (basal $v$ diffuse staining); the loss of basal staining represents a worse prognostic marker indicating a poorly differentiated tumour [10].

In our previous preliminary study [17] we have described the usefulness of the bivariate cytokeratin 7/DNA analysis and flow cytometric measurement of 


\section{Expression of fMIB-1 values in diploid and aneuploid tumors}

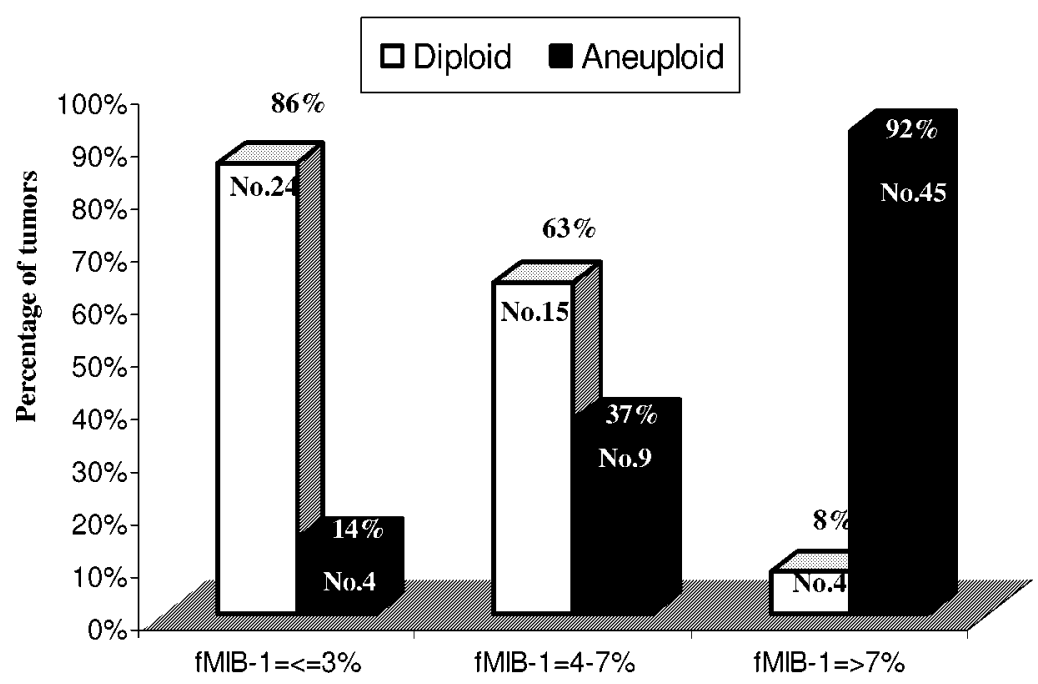

Fig. 8. Expression of flow MIB-1 values in diploid and aneuploid tumors.

Correlation between flow MIB-1 labeling indices and SPF values

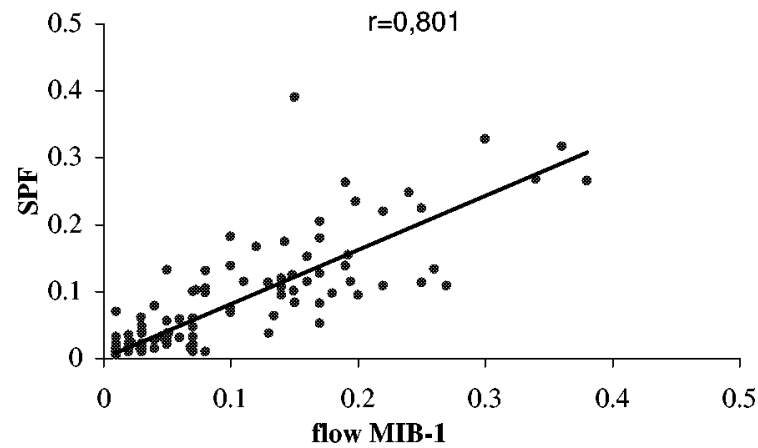

(a)
Correlation between flow MIB-1 labeling indices and S+G2M

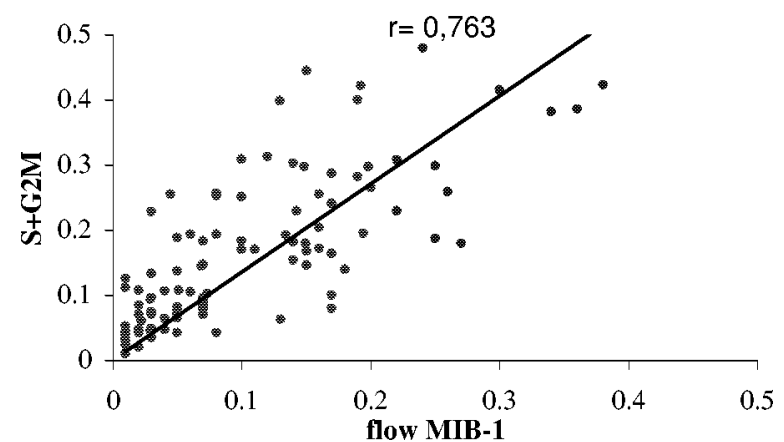

(b)

Fig. 9. Linear regression showing the correlation between flow MIB-1 expression and SPF (9a) and S+G2M (9b) values.

MIB-1 in bladder cancer. However we did not investigate the correlation between fMIB-1 values and DNA aneuploidy or with $\mathrm{G} 2+\mathrm{M}$ fraction.

The purpose of our present work was to study the parameters which could be a risk for progression of the disease. We attempted also to verify if tumours with different DNA content were biologically characterised by different associations with unfavourable biomarkers. In order to reach these objectives a multiparameter flow cytometry and an immunohistochemical analysis were performed on tumour tissue. Flow cytometric analyses of DNA/cytokeratin 7 were helpful to obtain more accurate DNA ploidy and SPF values. In particular the bivariate approach avoided some possible mistakes regarding the histogram interpretation as in hypodiploid or in multiclonal cases.

The acquisition of more objective proliferation data in adjunct to cell cycle data analysis constituted a useful tool to understanding the true malignant biological potential of the superficial bladder cancer. Flow cytometric MIB-1 analysis represented a rapid and objective tool in quantifying cellular proliferation. 
In our laboratory the best method to fix and permeabilize the cellular suspensions was represented by methanol/acetone for $20 \mathrm{~min}$ as previously reported [17]. The method allowed us to examine a large number of cells in a short time. By use of an indirect immunostaining procedure we obtained enhancement of the fluorescent signal and reduced background staining. At the fluorescent microscope MIB-1 expression ranged from small bright intranuclear dots to some large, irregular shaped nucleoli, a staining pattern corresponding to cell cycle related changes of $\mathrm{Ki}-67$ antigen [29]. We found that flow cytometric MIB-1 data $>7 \%$ strongly correlated with aneuploidy suggesting that this parameter could be effective to discriminate tumours with high aggressive behaviour. We also observed a strong correlation between fMIB-1 data and flow cytometric proliferative values (SPF) demonstrating that fMIB-1 measurement provides an accurate and useful method to assess cellular proliferation comparable to the cell cycle analysis method. We suppose that the methanol/acetone procedure represents a method to selectively identify the cells in $S$ phase but thiscan only be confirmed by further parallel experiments with bromodeoxyuridine, similar to those conducted on the PCNA molecule [1]. Absence of significant correlations between fMIB-1 and immunohistochemical expression of MIB-1 in the corresponding tissue section could be ascribed to the different fixation protocol (buffered formalin $v$ methanol/acetone) or to a partial degradation of the MIB-1 epitope by proteolytic enzymes during thawing and mechanical disaggregation.

The diploid cases fell mostly in the lowest and medium tertile of fMIB-1. Interestingly in these groups the aneuploid cases were represented by tetraploid cases only, suggesting that some tetraploid tumors were characterised by a low cellular proliferation similar to diploid tumors while others showed a very high proliferation similar to hypertetraploid and multiclonal tumors.

Tetraploidy which is generally considered the first step in the process of aneuploidization $[8,9,32,34]$ appears to represent the ploidy class which benefits more from this analysis.

Data arising from our prospective study showed a strong correlation between aneuploidy and staging, grading, SPF value $\geqslant 5.5 \%$, MIB- 1 positivity $\geqslant 31 \%$ and score 2 of p53 expression. In agreement with published findings $[13,24,41]$ we observed that flow cytometry was particularly useful to discriminate a subgroup characterised by a more aggressive potential within grade 2 tumours. By stratifying the cases into six classes according to different DNA content we also attempted to identify a ploidy class with the worst biological profile being characterised by a MIB-1 value $\geqslant 31 \%$, SPF $\geqslant 5.5 \%$ and p53 score 2 expression. Although statistical analysis failed to demonstrate any significance, probably due to the low number of the patients in the classes it seemed worthwhile to note that the hypotetraploid class showed the highest percentage of cases with poor prognostic biomarkers. In fact $73 \%$ of the hypotetraploid tumors had MIB$1 \geqslant 31 \%, 91 \%$ showed SPF values $\geqslant 5.5 \%$ and $64 \%$ showed p53 score 2 . In addition to multiploidy and hypertetraploidy which are considered as highly aggressive ploidy abnormalities [33,39], hypotetraploidy also seems to represent a grave prognostic factor.

In conclusion the present prospective study suggests a strong potential role for flow cytometric and immunohistochemical methods in the biological assessment of bladder cancer behaviour. The determination of DNA content coupled with the study of the epithelial and proliferative components of the tumours could be useful in providing important information on the biological evolution of individual tumours. Biological markers such as DNA hypotetraploidy, high expression of $\mathrm{p} 53$, and high cellular proliferation $(\mathrm{SPF} \geqslant 5.5 \%$, MIB- $1 \geqslant 31 \%$, fMIB-1>7\%) could be critical factors in the acquisition of metastatic potential.

\section{Acknowledgements}

The authors wish to thank Dr. Federica Zamberlan of the Medac Diagnostika Valter Occhiena for kind gift of the antibody MIB-1.

We are grateful to Mrs Mara Dal Santo for her excellent technical assistance.

\section{References}

[1] T. Beppu, Y. Ishida, H. Arai, T. Wada, N. Uesugi and K. Sasaki, Identification of S-phase cells with PC10 antibody to proliferating cell nuclear antigen (PCNA) by flow cytometric analysis, J. Histochem. Cytochem. 42 (1994), 1177-1182.

[2] H. Bittard, B. Lamy and C. Billery, Clinical evaluation of cell deoxyribonucleic acid measured by flow cytometry in bladder cancer, J. Urol. 155 (1996), 1887-1891.

[3] C. Bush, P. Price, J. Norton, C.S. Parkins, M.J. Bailey, J. Boyd, C.R. Jones, R.P. A'Hern and A. Horwich, Proliferation in human bladder carcinoma measured by Ki-67antibody labelling: its potential clinical importance, Br. J. Cancer 64 (1991), 357360 . 
[4] A.S. Bustamante, M.A. Guervos, J.R. de los Toyos, F. Dolbeare and A. Sampedro, Comparative flow cytometric analysis of DNA-bound PCNA and DNA content as estimators of Sphase cells in cell cultures, Anal. Cell. Pathol. 11 (1996), 127136.

[5] J.A.W. Chapman, E. Wolman, S.R. Wolman, Y. Remvikos, S. Shackney, D.E. Axelrod, H. Baish, I.J. Christensen, R.A. White, L.S. Liebovitch, D.H. Moore, F.M. Waldman, C.J. Cornelisse and T. Shankey, Assessing genetic markers of tumour progression in the context of intratumour heterogeneity, Cytometry 31 (1998), 67-73.

[6] H.L. Cheng, N.H. Chow, T.S. Tzai, Y.C. Tong, J.S. Lin, S.H. Chan, W.H. Yang, C.C. Chang and Y.M. Lin, Prognostic significance of proliferating cell nuclear antigen expression in transitional cell carcinoma of the upper urinary tract, Anticancer Res. 17 (1997), 2789-2793.

[7] P.J. Van Diest, G. Brugal and J.P.A. Baak. Proliferation markers in tumours: interpretation and clinical value, J. Clin. Pathol. 51 (1998), 716-724.

[8] W. Giaretti, A model of DNA aneuploidization and evolution in colorectal cancer, Lab. Invest. 71 (1994), 904-910.

[9] W. Giaretti, Aneuploidy mechanisms in human colorectal preneoplastic lesions and Barrett's esophagus. Is there a role for K-ras and P53 mutations?, Anal. Cell. Pathol. 15 (1997), 99117.

[10] B. Helpap and J. Köllermann, Proliferative pattern of exophytic and superficially invasive and noninvasive low-grade urothelial carcinomas, Hum. Pathology 30 (1999), 145-150.

[11] S. Holmang, S. Hedelin, C. Anderstrom, and S.L. Johansson, The relationship among multiple recurrences, progression and prognosis of patients with stages TA and T1 transitional cell cancer of the bladder followed for at least 20 years, J. Urol. 153 (1995), 1823-1827.

[12] M.L.A. Hudson, P.E. Swanson, R.B. Nadler and P.A. Humphrey, P53 protein accumulation in superficial bladder cancer is predictor of subsequent muscle invasion, $J$. Urol. Pathology 2 (1994), 307-318.

[13] B. Kirkhus, O.P.F. Clausen, H. Fjordvang, K. Helander, O.H. Iversen, J.D. Reitan and S. Vaage, Characterisation of bladder tumours by multiparameter flow cytometry with special reference to grade II tumours, APMIS 96 (1988), 783-792.

[14] P. Korkolopoulou, P. Christodoulou, P. Kapralos, M. Exarchakos, A. Bisbiroula, M. Hadjiyannakis, C. Georgountzos and E. Thomas-Tsagli, The role of p53, MDM2 and c-erb B-2 oncoproteins, epidermal growth factor receptor and proliferation markers in the prognosis of urinary bladder cancer, Pathol. Res. Pract. 193 (1997), 767-775.

[15] J.K. Larsen, I.J. Christensen, J. Christiansen and B.T. Mortensen, Washless double staining analysis of DNA and a nuclear antigen (Ki-67 or bromodeoxyuridine), Cytometry 12 (1991), 429-437.

[16] S.E. Lee and M.S. Park, Prognostic factors for survival in patients with transitional cell carcinoma of the bladder: evaluation by histopathologic grade, pathologic stage and flow-cytometric analysis, Eur. Urol. 29 (1996), 193-198.

[17] E. Leonardi, A. Cristofori, A. Reich and P. Dallapalma, Bivariate analysis DNA/cytokeratin and flow cytometric measurement of MIB-1 in superficial transitional carcinoma of the bladder (TCC). Methodological aspects and prognostic implications, Eur. J. Histochemistry 41 (1997), 133-134.
[18] T. Liedl, Flow cytometric DNA/cytokeratin analysis of bladder lavage: methodical aspects and clinical implications, Urol. Int. 54 (1995), 22-47.

[19] P.K. Lipponen, M.J. Eskelinen and S. Nordling, Progression and survival in transitional cell bladder cancer: a comparison of established prognostic factors, S-phase fraction and DNA ploidy, Eur. J. Cancer 27 (1991), 877-881.

[20] P.K. Lipponen, Over-expression of p53 nuclear oncoprotein in transitional cell bladder cancer and its prognostic value, Int. J. Cancer 53 (1993), 365-370.

[21] T.J.O. Liukkonen, P.K. Lipponen, M. Helle, K.E. Jauhiainen and the Finnbladder III Group, Immunoreactivity of bcl-2, p53 and EGFr is associated with tumor stage, grade and cell proliferation in superficial bladder cancer, Urol. Res. 25 (1997), $1-8$.

[22] T.J.O. Liukkonen, P.K. Lipponen, M. Helle, H.K. Haapasalo, S. Nordling, P. Rajala and the Finnbladder Group, Expression of MIB-1, mitotic index and S-phase fraction as indicators of cell proliferation in superficial bladder cancer, Urol. Res. 24 (1996), 61-66.

[23] T. Liukkonen, P. Rajala, M. Raitanen, E. Rintala, E. Kaasinen, P. Lipponen for the Finnbladder Group, Prognostic value of MIB-1 score, p53, EGFr, mitotic index and papillary status in primary superficial (stage $\mathrm{pTa} / \mathrm{T} 1$ ) bladder cancer: a prospective comparative study, Eur. Urology 36 (1999), 393-400.

[24] S.B. Malkowicz Editorial: superficial bladder cancer - incremental insight, J. Urol. 155 (1996), 488-489.

[25] G. Mazzini, M. Danova, C. Ferrari, M. Giordano, P. Dionigi and A. Riccardi, Cell proliferation and ploidy of human solid tumours: methodological experience with in vivo bromodeoxyuridine and DNA flow cytometry, Anal. Cell. Pathol. 10 (1996), 101-113.

[26] R. Oyasu, L. Nan, R.C. Szumel, H. Kawamata and S. Hirohashi, p53 gene mutations in human urothelial carcinomas: analysis by immunohistochemistry and single-strand conformation polymorphism, Modern Pathology 8 (1995), 170-176.

[27] S. Preston-Martin, M.C. Pike, R.K. Ross, P.A. Jones and B.E. Henderson, Increased cell division as a cause of human cancer, Cancer Res. 50 (1990), 7415-7421.

[28] M.P. Raitanen, T.L.J. Tammela, M. Kallioinen and J. Isola, p53 accumulation, deoxyribonucleic acid ploidy and progression of bladder cancer, J. Urol. 157 (1997), 1250-1253.

[29] M.S. Santisteban and G. Brugal, Image analysis of in situ cell cycle related changes of PCNA and Ki67 proliferating antigen expression, Cell. Prolif. 27 (1994), 435-453.

[30] A.S. Sarkis, G. Dalbagni and C.R. Cordon-Cardo, Association of p53 nuclear overexpression and tumor progression in carcinoma in situ of the bladder, J. Urol. 152 (1994), 388-392.

[31] J. Serth, M.A. Kuczyc, C. Bokemeyer, C. Hervatin, R. Nafe, H.K. Tan and U. Jonas, p53 immunohistochemistry as an independent prognostic factor for superficial transitional cell carcinoma of the bladder, Br. J. Cancer 71 (1995), 201-205.

[32] S.E. Shackney, C.A. Smith, B.W. Miller, D.R. Burholt, K. Murtha and H.R. Giles, Model for the genetic evolution of human solid tumors, Cancer Res. 49 (1989), 3344-3354.

[33] S.E. Shackney, G. Berg, S.R. Simon, J. Cohen, S. Amina, W. Pommersheim, R. Yakulis, S. Wang, M. Uhl, C.A. Smith, A. Pollice, R.J. Hartsock, Origins and clinical implications of aneuploidy in early bladder cancer, Cytometry 22 (1995), 307316. 
[34] S.E. Shackney and T.V. Shankey, Common patterns of genetic evolution in human solid tumors, Cytometry 29 (1997), 1-27.

[35] S.R. Shi, M.E. Key and K.L. Kaira, Antigen retrieval in formalin fixed, paraffin embedded tissues: an enhancement method for immunohistochemical staining based on microwave oven heating of tissue sections, J. Histochem. Cytochem. 39 (1991), 741-748.

[36] H. Shiina, M. Igawa, H. Nagami, H. Yagi, S. Urakami, T. Yoneda, H. Shirakawa, T. Ishibe and M. Kawanishi, Immunohistochemical analysis of proliferating cell nuclear antigen, $\mathrm{p} 53$ protein and nm23 protein, and nuclear DNA content in transitional cell carcinoma of the bladder, Cancer 78 (1996), 1762-1774

[37] M. Soloway, Managing superficial bladder cancer: an overview, Urology 40(Suppl.) (1992), 5-10.

[38] K. Steck and A.K. El-Naggar, Comparative flow cytometric analysis of Ki-67 and proliferating cell nuclear antigen (PCNA) in solid neoplasms, Cytometry 17 (1994), 258-265.

[39] M. Tachibana, N. Deguchi, S. Baba, S. Jitsukawa, M. Hata and H. Tazaki, Multivariate analysis of flow cytometric deoxyribonucleic acid parameters and histological features for prognosis of bladder cancer patients, J. Urol. 146 (1991), 1530-1534.

[40] L.L. Vindelov, I.J. Christensen, S.A. Engelholm, B.H. Guldhammer, K. Hojgaard, B. Sorensen and H. Wolf, Prognostic significance of DNA content in bladder cancer on flow cyto- metric analysis of 249 transitional cell carcinomas, Cytometry 22 (1995), 93-102.

[41] L.L. Wheeless, R.A. Badalament, R.W. de Vere White, Y. Fradet and B. Tribukait, Consensus review of the clinical utility of DNA cytometry in bladder cancer, Cytometry 14 (1993), 478-481.

[42] L. Wu, A. Lochhead, J. Yang, K.T. Ow and P.J. Russel, DNA-flow cytometric analysis of bladder TCC using paraffinembedded tissue, Urol. Int. 60 (1998), 208-215.

[43] R.J. Zarbo, D.W. Vissher and J.D. Crissman, Two-colormultiparametric method for flow cytometric DNA analysis of carcinomas using staining for cytokeratin and leukocytecommon antigen, Anal. Quant. Cytol. Histol. 11 (1989), 391402.

[44] A.R. Zlotta, J.C. Noel, I. Fayt, A. Drowart, J.P. Van Vooren, K. Huygen, J. Simon and C. C. Schulman, Correlation and prognostic significance of p53, p21 WAF/CIP1 and Ki-67 expression in patients with superficial bladder tumors treated with Bacillus Calmette-Guerin intravescical therapy, J. Urol. 161 (1999), 792-798.

[45] F. Zolzer, C. Streffer and T. Pelzer, A comparison of different methods to determine cell proliferation by flow cytometry, Cell. Prolif. 27 (1994), 685-694. 


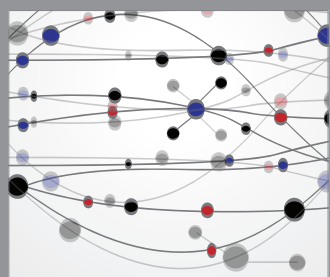

The Scientific World Journal
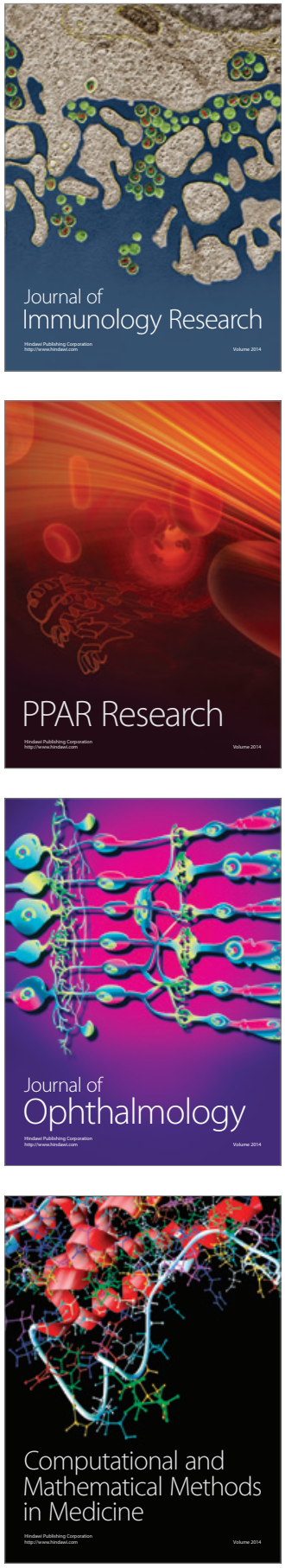

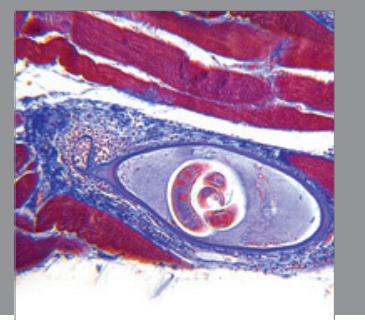

Gastroenterology

Research and Practice
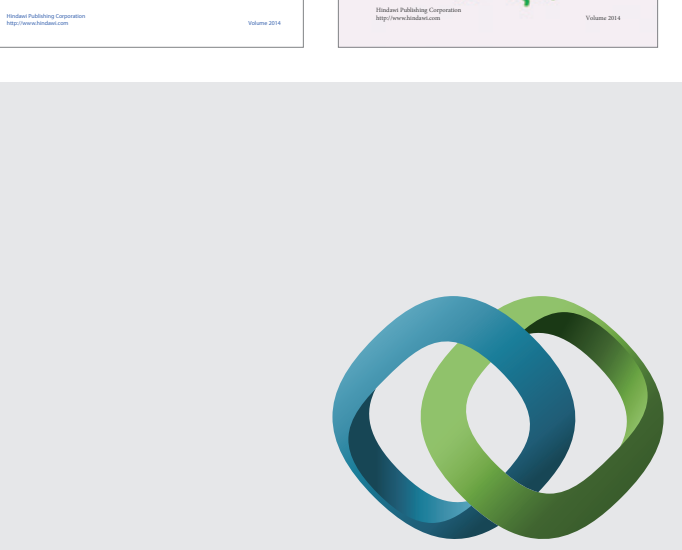

\section{Hindawi}

Submit your manuscripts at

http://www.hindawi.com
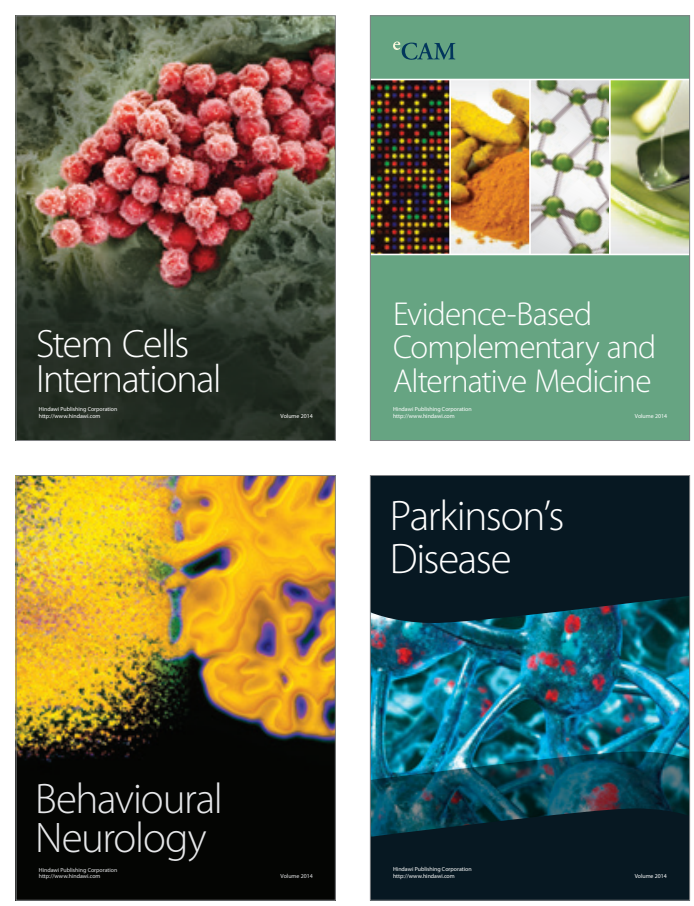

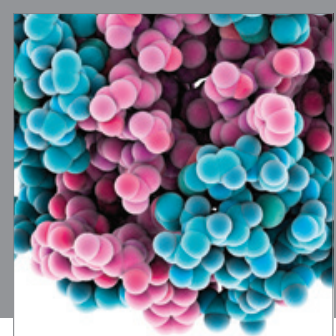

Journal of
Diabetes Research

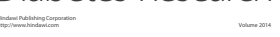

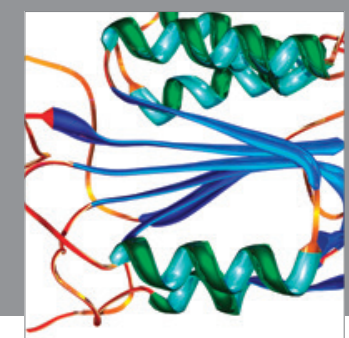

Disease Markers
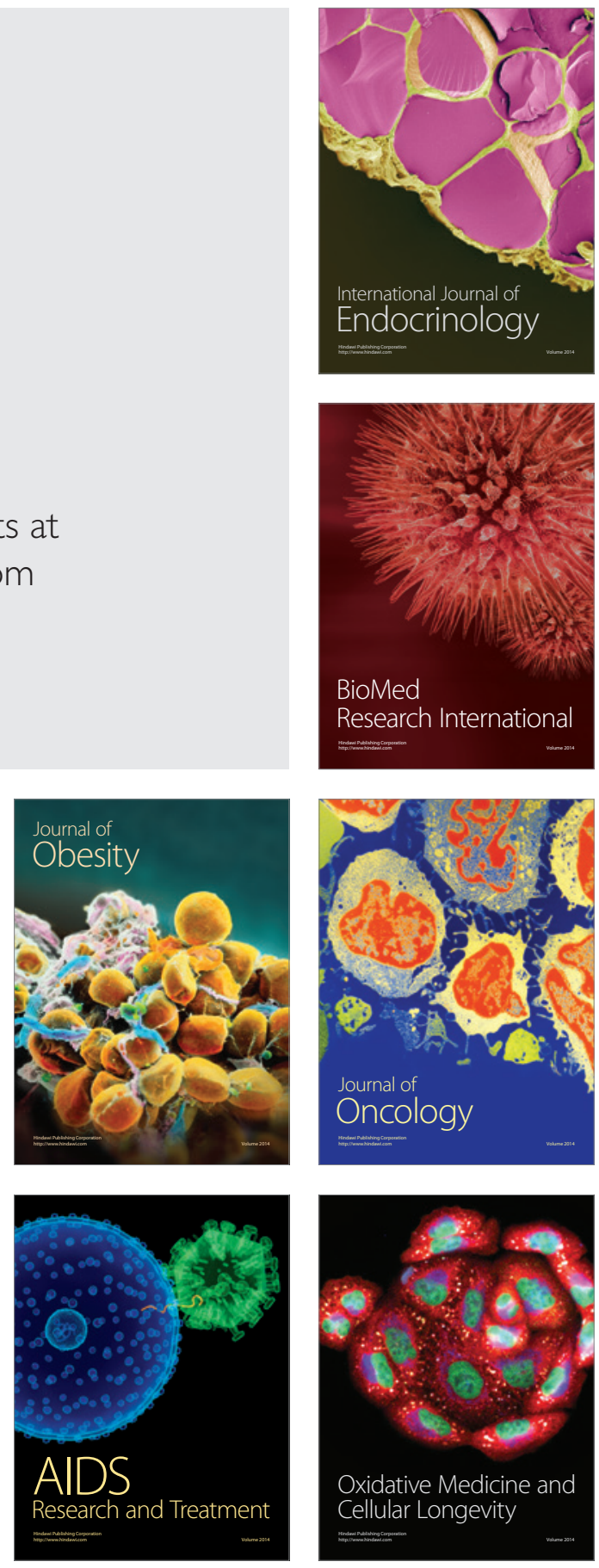